\title{
Etiology and maternofetal issue of acute pulmonary edema in prepartum at the Befelatanana University Hospital of Gynecology and Obstetrics
}

\section{Randriamahavonjy Romuald ${ }^{1 *}$, Ratsiatosika A. Tanjona², Sidy Fleurian², Housni Ibrahim²}

${ }^{1}$ Department of Gynecology-Obstetrics in the Soavinandriana Hospital Center of the Faculty of Medicine Antananarivo, Madagascar

${ }^{2}$ Department of the faculty of Medicine, Public Health Department, Antananarivo, Madagascar

Received: 30 May 2018

Accepted: 28 June 2018

\section{*Correspondence:}

Dr. Ratsiatosika A. Tanjona,

E-mail: ratsiatosika.tanjona@gmail.com

Copyright: (C) the author(s), publisher and licensee Medip Academy. This is an open-access article distributed under the terms of the Creative Commons Attribution Non-Commercial License, which permits unrestricted non-commercial use, distribution, and reproduction in any medium, provided the original work is properly cited.

\section{ABSTRACT}

Background: Pulmonary edema is defined as the as the ultrafiltration of plasma through the capillary wall to the interstitium and pulmonary alveoli. It is a rare pathology and difficult diagnosis. Through this study, we wanted to know the etiologies and maternofetal issue of acute pulmonary edema manifesting in prepartum. It is a rare pathology and difficult diagnosis. Through this study, we wanted to know the causes and maternofetal issue of acute pulmonary edema manifested in prepartum.

Methods: It is about a descriptive retrospective study from January 1st, 2014 to April 30th, 2018 at the Befelatanana University Hospital of Obstetrics and Gynecology. We included all pregnant patients of 20 weeks and above with acute antepartum pulmonary edema. We excluded postpartum APE. Data collection and analysis was performed on the Excel Stat 2007 Software.

Results: We had 36 cases of acute pulmonary edema during this period with an incidence of $0.001 \%$. The average age was $28.75 \pm 8.72$ years. Mean gestational age was $32 \pm 7.82$ SA. Pregnancy was poorly followed in more than half of the cases. $15 \%$ did not perform prenatal follow-up. Caesarean section was the chosen delivery route in $82 \%$ of cases. Among the childbirth, 73\% were premature, 63\% asphyxiated and 56\% hypotrophic. We had 52\% of maternal death and $44,44 \%$ of fetal loss. The main etiology was dominated by preeclampsia and its complications $(63.88 \%)$ followed by cardiopathy $(25 \%)$. A case of malaria during pregnancy was identified as the cause of APE.

Conclusions: Acute pulmonary edema during pregnancy is a serious pathology because the maternal prognosis is catastrophic with $50 \%$ maternal and foetal mortality in our context. The identification of patients at risk, the monitoring of pregnancy, the effective management of the pathology involved are necessary to reduce the incidence and maternal mortality secondary to pulmonary edema.

Keywords: Eclampsia, Dyspnea, Pulmonary edema, Severe pre-eclampsia

\section{INTRODUCTION}

Acute pulmonary edema (APE) is defined by plasma ultra-filtering across the capillary wall towards the interstitium and the pulmonary alveoli associated with excessive pulmonary capillary pressure (hemodynamic APE) or a pathological increase of the permeability of the alveolar-capillary membrane (APE lesional). It is a rare complication of pregnancy with $0.08 \%$ of cases according to a retrospective study for more than 67,000 deliveries. ${ }^{1}$ 
The diagnosis is often difficult. Hemodynamic changes in pregnancy could also play a role favoring preload by means of an increase of (physiological hypervolemia) and post-loading in case of high blood pressure. The aim of this work was to describe the prognosis of maternal fetal, incidence and causes of acute pulmonary edema in pregnant women. The knowledge of these parameters will improve the diagnostic and therapeutic monitoring of APE in parturient and its prevention.

\section{METHODS}

It is about a descriptive retrospective study from the first of January 2014 to April 30th, 2018 at CHUGOB. Authors included all pregnant patients above 20 weeks with antepartum acute pulmonary edema. We excluded postpartum APE. The collection and analysis of the data was done on the Excel Stat 2007 Software. The parameters studied were: obstetric parameters which are the sex of the newborn, the birth weight, the gestational age, the delivery route, the presence or absence of hydramnios, the appearance of amniotic fluid, intrauterine growth retardation.

Then the parameters of the newborn, which included the number of intrauterine fetal death (IUFD), the Apgar score in the fifth minute, and admission to intensive neonatal care unit. And, the maternal parameters as follows age, parity, number of consultation for pregnancy monitoring, marital status, medical history, history of stillbirths, neonatal deaths, uterine height, existence of fever during labor, blood pressure, tocolysis and antenatal corticosteroid therapy, length of stay in Hospital and in intensive care unit, type of APE, presence of obstetric pathologies such as retro placental hematoma (RPH ), Placenta praevia, preeclampsia, eclampsia, HELLP (Hemolysis, Elevated Liver Enzyme and Low Platelet) Syndrome, renal failure nephropathy, clinical signs of anemia, and transfusions; postpartum hemorrhage and maternal deaths with their causes. And finally, the etiology of APE.

\section{RESULTS}

During this period, we had 27,189 deliveries. Among these, 36 acute pulmonary edemas were reported, that is to say an incidence of $0.001 \%$.

The average maternal age was $28.75 \pm 8.72$ years with $11 \%$ of adolescent. Only $57 \%$ are married. The average parity was $1.91 \pm 1.82$. We had $34 \%$ of primiparous and $7 \%$ of multiparous.

Among the 36 cases, $15 \%$ had never done prenatal follow-up, $58 \%$ had irregular follow-up presented symptoms of APE. There was no post-transfusion APE. We had systolic blood pressure $>160$ mmh in $37 \%$ of patients and PAS ranging from 140 to $160 \mathrm{mmhg}$ in $16 \%$; $28 \%$ had a diastolic blood pressure $>110 \mathrm{mmhg}, 8 \%$ had a PAD between 90 to $110 \mathrm{mmhg}$ on admission (Table 1).
Table 1: Maternal characteristics.

\begin{tabular}{|c|c|c|}
\hline Variables & & $\mathrm{n}=36(\%)$ \\
\hline \multirow{3}{*}{ Age } & $<18$ years & $4(11.11 \%)$ \\
\hline & 18-35 years & $22(61.11 \%)$ \\
\hline & $>35$ years & $10(27.78 \%)$ \\
\hline \multirow{3}{*}{ Parity } & Primipara & $9(34.62 \%)$ \\
\hline & Parity 2-5 & $15(57.69 \%)$ \\
\hline & Multipara (>5) & $2(7.69 \%)$ \\
\hline \multirow{3}{*}{ Marital status } & Married & $20(55.55 \%)$ \\
\hline & Single & $2(5.57 \%)$ \\
\hline & Concubinage & $14(38.88 \%)$ \\
\hline \multirow{3}{*}{$\begin{array}{l}\text { Number of } \\
\text { prenatal } \\
\text { consultation }\end{array}$} & 0 & $5(13.88 \%)$ \\
\hline & $1-3$ & $21(58.33 \%)$ \\
\hline & $\geq 4$ & $10(27.79 \%)$ \\
\hline \multirow{5}{*}{ Medical history } & $\begin{array}{l}\text { Without a particular } \\
\text { antecedent }\end{array}$ & $26(72.24 \%)$ \\
\hline & $\begin{array}{l}\text { High blood } \\
\text { pressure }\end{array}$ & $6(16.66 \%)$ \\
\hline & Cardiopathy & $2(5.55 \%)$ \\
\hline & $\begin{array}{l}\text { Pulmonary } \\
\text { (pneumopathy) }\end{array}$ & $2(5.55 \%)$ \\
\hline & $\begin{array}{l}\text { antecedent's intra- } \\
\text { uterine fetal } \\
\text { deaths/neonatal } \\
\text { deaths }\end{array}$ & $2(5.55 \%)$ \\
\hline \multirow{3}{*}{$\begin{array}{l}\text { Systolic blood } \\
\text { Pressure }\end{array}$} & $<140 \mathrm{mmhg}$ & $17(47.22 \%)$ \\
\hline & 140-160mmhg & $6(16.66 \%)$ \\
\hline & $>160 \mathrm{mmhg}$ & $13(36.12 \%)$ \\
\hline \multirow{3}{*}{$\begin{array}{l}\text { Diastolic blood } \\
\text { Pressure }\end{array}$} & $<90 \mathrm{mmhg}$ & $18(50 \%)$ \\
\hline & 90-110mmhg & $8(22.23 \%)$ \\
\hline & $>110 \mathrm{mmhg}$ & $10(27.77 \%)$ \\
\hline \multirow{3}{*}{ Therapeutic } & Tocolysis & $3(8.33 \%)$ \\
\hline & $\begin{array}{l}\text { Antenatal } \\
\text { corticotherapy }\end{array}$ & $4(11.11 \%)$ \\
\hline & $\begin{array}{l}\text { Blood transfusion } \\
\text { before APE }\end{array}$ & $2(5.55 \%)$ \\
\hline \multirow{2}{*}{ APE type } & Cardiogenic & $6(16.67 \%)$ \\
\hline & Non-cardiogenic & $30(83.33 \%)$ \\
\hline \multirow{3}{*}{$\begin{array}{l}\text { Obstetrical } \\
\text { pathology }\end{array}$} & Preeclampsia & $14(38.88 \%)$ \\
\hline & Eclampsia & $9(25 \%)$ \\
\hline & Hellp syndrom & $2(5.55 \%)$ \\
\hline \multirow{2}{*}{$\begin{array}{l}\text { Maternal } \\
\text { outcomes }\end{array}$} & Renal insufficient & $5(13.88 \%)$ \\
\hline & Clinical anemia & $8(22.22 \%)$ \\
\hline \multirow{5}{*}{$\begin{array}{l}\text { Cause of } \\
\text { maternal deaths }\end{array}$} & Eclampsia & $7(36.84 \%)$ \\
\hline & $\begin{array}{l}\text { Severe pre- } \\
\text { eclampsia }\end{array}$ & $2(10.52 \%)$ \\
\hline & $\begin{array}{l}\text { Decompensating } \\
\text { cardiopathy }\end{array}$ & $5(26.31 \%)$ \\
\hline & $\begin{array}{l}\text { Infection } \\
\text { (chorioamnionitis } \\
+ \text { severe sepsis) }\end{array}$ & $2(10.52 \%)$ \\
\hline & Unexplained & $3(15.81 \%)$ \\
\hline
\end{tabular}

Regarding the obstetrical characteristics, $73 \%$ were premature of which $12 \%$ of the patients benefited of a pulmonary maturation and $9 \%$ of tocolysis. In present study male new-borns predominate over females, which 
accounting for $70 \%$ of cases. We had $83.78 \%$ cesarean section. Gestational age average was $32 \pm 7.82 \mathrm{SA}$. Amniotic fluid was clear in $78 \%$ of cases. The average of birth weight was $2166.4 \pm 1117.4 \mathrm{~g}$, and $56 \%$ of neonatal hypotrophy (Table 2).

Table 2: Obstetrical parameters.

\begin{tabular}{|c|c|c|}
\hline Variables & & $\mathrm{n}=36(\%)$ \\
\hline \multirow{2}{*}{ New born gender } & Male & $21(70)$ \\
\hline & Female & $9(30)$ \\
\hline \multirow{4}{*}{ Birth weight } & Mean $( \pm$ sd $)$ & $\begin{array}{l}2166.4 \pm \\
1117.4 \mathrm{~g}\end{array}$ \\
\hline & $1500-2500 \mathrm{~g}$ & $15(57,69 \%)$ \\
\hline & $\leq 1500 \mathrm{~g}$ & $7(25.94 \%)$ \\
\hline & $>2500 \mathrm{~g}$ & $12(44.44 \%)$ \\
\hline \multirow{4}{*}{$\begin{array}{l}\text { Gestational age } \\
( \pm \mathrm{sd})\end{array}$} & Mean $( \pm s d)$ & $32 \pm 7.82 \mathrm{SA}$ \\
\hline & $<37 \mathrm{SA}$ & $25(73.52 \%)$ \\
\hline & 37-41SA & $8(23.54 \%)$ \\
\hline & 41SA & $1(2.94 \%)$ \\
\hline \multirow[t]{2}{*}{ Delivery route } & Cesarean & $30(82.36 \%)$ \\
\hline & Natural route & $6(17.64 \%)$ \\
\hline \multirow{4}{*}{ Amniotic liquid } & clear & $23(76.66 \%)$ \\
\hline & Meconial & $4(13.35 \%)$ \\
\hline & Fetid & $2(6.66 \%)$ \\
\hline & Blood & $1(3.33 \%)$ \\
\hline \multicolumn{2}{|c|}{ Intrauterine growth retardation } & $5(19.24 \%)$ \\
\hline
\end{tabular}

Neonatal admissions were $53 \%$, of which $73 \%$ were prematurity and $63 \%$ were newborns with neonatal asphyxia. Amniotic fluid was clear in $78 \%$ of cases. Half of the fetal deaths were in utero (Table 3 ).

Table 3: Neonatal outcomes.

\begin{tabular}{|ll|}
\hline Variables & $\mathrm{n}=36(\%)$ \\
\hline Neonatal asphyxia (apgar <7 à M5) & $23(63.88 \%)$ \\
\hline Admission to neonatal resuscitation & $14(53.84 \%)$ \\
\hline Intrauterine fetal death / neonatal death & $16(50 \%)$ \\
\hline Premature & $25(73.52 \%)$ \\
\hline
\end{tabular}

Etiologically we had $16 \%$ of cardiogenic APE cases and $84 \%$ of non-cardiogenic APE. In the history of these patients $9 \%$ had heart disease, $17 \%$ had high blood pressure, and $5 \%$ had stillbirths. The main cause of APE in pregnant women was severe pre-eclampsia and its complications ( $64 \%$ of cases) associated with eclampsia in $25 \%$ of cases and HELLP Syndrome in $7 \%$ of cases. Only 5\% were transfused into patients who had already APE. These patients with severe pre-eclampsia or eclampsia had not been treated with magnesium sulphate. Heart disease was observed in six patients (16\% of cases) and was the second leading cause of APE from present study: four patients had never known heart disease prior to pregnancy, one of which was unknown, while only two patients were carriers. Tight mitral stenosis already known before pregnancy. Apart from this, there are two cases of peripartum heart disease or isolated heart failure. The third etiology was infection up to $14 \%$ of the parturient, predominantly with pulmonary infection with severe pneumonitis (three cases), chorioamnionitis with severe sepsis (one case) and one case of severe Plasmodium falciparum malaria. In addition, only one case of fever during labor occurred in an eclamptic patient, but the etiology of APE was not infectious in this vascular context. The last etiology was acute renal failure presented in one patient, i.e. 3\% of cases. Apart from this, we had noticed a renal insufficiency, from three eclamptic patients and another in a cardiopathic (tight MR) without being the cause of APE but an aggravating factor. On the other hand, we did not find certain etiology in $4 \%$ of the patients (two cases), because they died on admission, consequently no clinical and paraclinical investigation on the source of their APE could be made.

The APE of the three patients who received tocolysis were from severe preeclampsia (two cases) and severe pneumonia (one case). The direct cause was not therefore related to tocolysis. The average duration length of stay in the Intensive Care Unit was $1.6 \pm 0.7$ days. The patients were subsequently transferred to the Cardiology Service after an average hospital stay of $5.6 \pm 1.09$ days in the maternity ward.

The evolution of this disease was unfavorable, because of the hospitalization in Intensive Care Unit (ICU) and in treatment management we still have $52 \%$ of maternal deaths. The first cause of death was pre-eclampsia and its complications (46\%) followed by decompensating of preexisting cardiopathy (26\%) such as mitral valve disease $(10 \%)$, isolated heart failure $(10 \%)$; and cardiopathy was unknown (6\%). Acute endometritis-type infection and acute renal failure were each responsible for $5 \%$ of maternal deaths. And from the rests of $18 \%$ we did not find the actual cause of APE that led to maternal death.

Table 4: Etiology of acute pulmonary edema in pregnant women.

\begin{tabular}{|lll|}
\hline Variables & $\mathrm{n}=36(\%)$ \\
\hline Preeclampsia & $14(38.88 \%)$ \\
\hline Eclampsia & $9(25 \%)$ \\
\hline Cardiopathy & & $9(25 \%)$ \\
\hline \multirow{2}{*}{ Infection } & Malaria & 1 \\
& Chorioamniotitis & 1 \\
\cline { 2 - 3 } & Pneumotitis & 3 \\
\hline Unexplained & & $2(5,55 \%)$ \\
\hline
\end{tabular}

\section{DISCUSSION}

From present study, the incidence of APE in prepartum was $0.001 \%$. In Tunisia, APE occurs during pregnancy of $0.05 \% .^{2}$ In developed countries, it varies from $0.05 \%$ to $0.08 \% .^{1,3-5}$ The incidence of APE in present study was lower because we gathered only those forms that occur in prepartum. For some authors, this form is the most common. ${ }^{1,3,6}$ On the other hand, Sibai and al found that secondary APE with preeclampsia manifest themselves in postpartum in $70 \%$ of cases. ${ }^{7}$ Furthermore, APE causes 
such as the use of tocolytics, excess of Iatrogenic fluid overload and transfusion were not identified in present study population

In this study case, these patients were poorly followed. $15 \%$ were never followed, more than half of $(58 \%)$ had less than four follow-ups. For a pathological pregnancy, with heart disease and preeclampsia, this number is largely insufficient. Even in patients with heart disease, no preconception visits were performed. Among these, two patients had previously been diagnosed with severe mitral stenosis. This shows poor quality monitoring of pregnancy in Madagascar and is a major problem in terms of public health. At-risk pregnancies should be referred to the obstetrical hospital. The average maternal age was $28.75 \pm 8.72$ years. This is similar to the data in the literature. The average age varies between 27 and 32 years old. No link explains the occurrence of the APE on this age group.

APE occurs previously in present study case on the average of $32 \pm 7.82$ weeks. The onset was earlier in case of preeclampsia $(31.09 \pm 7.84$ weeks). In case of cardiopathy, the average gestational age was 33.28 \pm 7.93 weeks. Present study case is identical to the Huang and al in Taiwan (32.8 weeks) as well as in developed countries. ${ }^{1,3,8-10}$ In fact, the maternal blood volume reaches its maximum at 32 weeks. This is around 45 to $50 \%$ of the initial maternal blood volume. the increase in myocardial labor promotes the decompensating of latent cardiopathy before pregnancy. ${ }^{11,12}$ Pre-existing cardiopathies, cause a risk of decompensating. In our context, it is most often a rheumatic heart disease. APE represents an immediate fetal extraction criterion. It is also a criterion of severity especially in case of preeclampsia. It is often a prematurity most induced at a very early age.

The average parity in present study case was: $1.91 \pm 1.82$, of which $34 \%$ were primiparous. In Taiwan, this rate was $26.66 \% .^{8}$ The latter was higher in Australia and Canada, the primiparous were observed in $68 \%$ and $89.7 \%$ of cases respectively. ${ }^{10,13}$ The first pregnancy can indeed decompensate underlying heart disease. Ghandi and al found that multiparty is a protective factor for APE occurrence during preeclampsia. ${ }^{13}$ For these reasons, more APEs are observed in primiparous women.

Regarding the delivery route, caesarean section seems to be most appropriate for acute pulmonary edema. Dwyer and al found $83 \%$ caesarean section for cardiogenic APE and $86 \%$ for APE secondary to preeclampsia. ${ }^{14}$ In Caen, France, caesarean section was the only route of delivery selected if APE is manifested as antepartum. ${ }^{3}$ In Australia, $68 \%$ of patients had a caesarean section. ${ }^{10}$ Scission reported $37.25 \%$ caesarean section. However, in their studies, they included postpartum APE. ${ }^{1}$ In present study, $83.78 \%$ of studied patients had a caesarean section. The rest $(16.22 \%)$ was delivered naturally or assisted by instrumental extraction. In our practice, in front of a APE, authors recommend caesarean section except if the labour is advanced with complete cervical dilatation. In this case, an instrumental extraction will be performed if the pregnancy exceeds 34 weeks. In our context, APE does not occur in hospitalized patients or in patients treated at the hospital. Patients were often referred or admitted directly to the emergency department. These six patients who were natural deliverers already had advanced cervical dilatation on admission.

$56 \%$ of newborns were born with low birth weight, half of whom had less than $1500 \mathrm{~g}$. Note also that the frequency of confirmed intrauterine growth restriction was $20 \%$. The frequency of prematurity and intrauterine growth restriction increases the number of hypotrophy in this study. This is consistent with studies in Taiwan and Caen, South Africa. ${ }^{3,8,14}$ where neonates born to mothers with secondary APE are often hypotrophic with an average body weight not exceeding $2500 \mathrm{~g}$ at birth. In fact, severe preeclampsia, which was the leading cause of APE in this study, is manifested in the fetus by intrauterine growth retardation, a sign of chronic fetal distress.

The placental insufficiency results in a defect of fetal infusion. All of this contributes to the high frequency of intrauterine growth retardation in this study. Thus, maternal pathologies underlying APE such as preeclampsia and its complications, mitral stenosis have a serious impact on the fetus, the most to be feared is perinatal asphyxia which is $63.88 \%$ in present study.

According to Huang et al in Taiwan, perinatal asphyxia assessed with the APGAR score varies according to the contexts and etiologies of APE observed: in case of postpartum haemorrhage the average APGAR score at the fifth minute was 8.6; during pre-eclampsia it is $6.6 \pm 3.2$ while in case of tocolytic use the score was $4.3 \pm 4.5 .^{8}$

Perinatal asphyxia results in a high perinatal death of $50 \%$ in present study; In contrast, Dwyer in South Africa reported $21 \%$ perinatal death by APE on underlying maternal High Blood Pressure, particularly pre-eclampsia and its complications; while Habli and al reported 3.3\% of perinatal deaths among mothers with APE. ${ }^{9,14}$

APE during pregnancy is generally divided into two groups, cardiogenic and non-cardiogenic. The main etiology was dominated by pre-eclampsia and its complications. This testifies to the seriousness of these pathologies on admission. This is similar to studies conducted in South Africa, in Ohio (USA), Caen where preeclampsia is the first cause of APE during pregnancy. $3,9,14$ According to Dolley et al, APE complicates $2.9 \%$ of preeclampsia and then imposes delivery. ${ }^{3}$ In this study, six cases of eclampsia were identified. From these, there was both a HELLP (Hemolysis, Elevated Liver Enzym and Low Platelet) syndrome and a patient with acute renal failure. During 
PE, acute pulmonary edema is often multifactorial. The brutal volume overload is often the cause. This is due to the return of interstitial fluids in the intravascular compartment early postpartum, and iatrogenic by significant fluid intake intravenous. Previously, volume expansion was considered a treatment for preeclampsia, but recently it is deleterious to the mother and causes pulmonary edema. ${ }^{10,15}$ Rarely, there is left ventricular dysfunction and an increase in peripheral vascular resistance. ${ }^{16.17}$ Cardiac dysfunction during preeclampsia is diastolic dysfunction, with increased left ventricular volume at the end of systole and at the end of diastole. There is also myocardial ischemia and ventricular arrhythmias, in particular ventricular tachycardia. All this contributes to the occurrence of heart failure. ${ }^{18}$ The activation of the sympathetic nervous system causes a peripheral vasoconstriction and secondarily a vascular redistribution towards the pulmonary circulation. Hypoxemia, accumulation of alveolar fluids, compensatory cardiac manifestations and myocardial ischemia are observed. ${ }^{19}$ Another cause is the reduction of the oncotic pressure by the proteinuria sometimes too important. This is not sufficient to trigger APE during pre-eclampsia but would be a contributing factor. ${ }^{20}$

Cardiogenic APE accounted for $16 \%$ of cases. These heart diseases were most often discovered at the stage of decompensating. Present study finding was identical to that of O'Dwyer and al. $11 \%$ had heart disease of which only one had been identified as antepartum. ${ }^{14}$ Even in developed countries, such as the United States, half were unidentified before pregnancy. ${ }^{1}$ Present study confirms the data from the literature. Heart disease during pregnancy remains dominated by mitral stenosis. ${ }^{21}$ These latent cardiopathies are infectious complications that occur during childhood. The incidence of this pathology is 6 per 1,000 in the pediatric environment. ${ }^{22}$ Indeed, there is an accommodation of the maternal cardiovascular function during pregnancy in relation to the fetal need. Cardiac output is $30-50 \%$ higher than in non-pregnant women. ${ }^{17,23}$ The increase of the myocardial work would favor this decompensating. In addition, three causes related to pregnancy are identified as a risk factor for decompensating of heart failure: preeclampsia, peripartum cardiomyopathy, amniotic embolism. Note that maternal morbidity and mortality related to this disease is serious. Cardiogenic APE was the leading cause of maternal death in the UK between 2006-2008. ${ }^{24}$

Infections are the third leading cause of APE in this study. The peculiarity is the existence of malaria as etiology. Among the studies looking for the etiology of APE, present study is the first to evoke malaria in pregnant women. Etiologies such as tocolytic uptake, iatrogenic volemic overloads were not found in present study. However, for Sciscione et al, Jabali et al, tocolytic drugs were the leading cause of APE. ${ }^{1,2}$ The local protocol uses nifedipine for tocolysis. It has been shown that patients with pulmonary edema after tocolytics are especially those who have received several tocolytics at once. $^{1}$

Half of the patients (52\%) who had acute pulmonary edema died as a result of the complications. This rate remains very high compared to the data of the literature. The patient may have died as a result of complications of the APE or its cause. It should be noted that these patients were seen at advanced stages of the pathology and associated with other complications such as eclampsia, retroplacental hematoma, often with multi-organ failure. Among these deaths, $46 \%$ were associated with preeclampsia. seven out of nine eclampsia cases had died. However, mortality secondary to heart disease remains the highest. five out of six had died. In South Africa, the occurrence of APE is a determinant of maternal mortality. ${ }^{25} 30 \%$ of maternal deaths secondary to hypertension during pregnancy are thought to be related to the occurrence of APE. ${ }^{26}$ In our opinion, this is the first study of APE in pregnancy that caused very high maternal mortality. A Taiwanese study found only $6.66 \%$ of maternal deaths. ${ }^{8}$ In the United States, Sciscione and al. Reported only $1.96 \%$ of maternal deaths secondary to pulmonary infection in a diabetic patient. ${ }^{1}$

The average hospital stay was 5.6 days in our center. These patients were subsequently referred to the cardiology department or directly to home if the respiratory status improved. Thornton and al, found an average duration of 7 days. ${ }^{10}$

Present study has its limits. Many cases did not benefit from echocardiography. Some etiologies could not be explored. There may be patients with a history of heart disease who had been decompensated by preeclampsia

Acute pulmonary edema during pregnancy is rare in Madagascar and the etiology is dominated by preeclampsia. It is a serious pathology because the maternal prognosis is catastrophic with $50 \%$ of maternal and fetal mortality in our context. The identification of patients at risk, the monitoring of pregnancy, the effective management of the pathology involved are urgent to reduce the incidence and maternal mortality secondary to APE. The improvement of resuscitation structures seems necessary to us.

\section{Funding: No funding sources Conflict of interest: None declared \\ Ethical approval: The study was approved by the Institutional Ethics Committee}

\section{REFERENCES}

1. Sciscione AC, Ivester T, Largoza M, Manley J, Shlossman P, Colmorgen GH. Acute pulmonary edema in pregnancy. Obstet Gynecol. 2003;101:5115

2. Jebali F, Meddeb B, Achech W, Cherif R, Hajji A, Jlaili A, et al., Acute pulmonary edema in obstetrics: 
a descriptive study of 16 cases and review of the literature. Anesthesia and Resuscitation. 2015;1:A204-5.

3. Dolley P, Lebon A, Beucher G, Simonet T, Herlicoviez M, Dreyfus M. Acute pulmonary edema and pregnancy: a descriptive study of 15 cases and review of the literature. J Gynecol Obstet Biol Reprod. 2012; 41:638-44.

4. Choi HS, Choi H, Han S, Kim HS, Lee C, Kim YY and al. Pulmonary Edema During Pregnancy Unilateral Presentation Is Not Rare. Circ J.2002; 66:623-6

5. Taghavi S, Rahmani V. Pulmonary edema complicating pregnancy. Int $\mathbf{J}$ Gynecol Obstet. 2009;917:S354.

6. Mabie WC, Hackman BB, Sibai BM. Pulmonary edema associated with pregnancy: echocardiographic insights and implications for treatment. Obstet Gynecol. 1993;81:227-34

7. Sibai BM, Mabie BC, Harvey CJ, Gonzalez AR. Pulmonary edema in severe preeclampsia-eclampsia: analysis of thirtyseven consecutive cases. Am J Obstet Gynecol. 1987;156:1174-9.

8. Huang WC, Chen CP. Pulmonary edema in pregnancy. Int J Gynecol Obstet. 2002;78:241-3.

9. Habli M, Radomile T, Bombrys A, Barton JR, How $\mathrm{H}$, Sibai B. Maternal outcomes of 126 pregnancies with acute pulmonary edema. AJOG. 2007. S117.

10. Thornton CE, Dadelszen PV, Makris A, Tooher JM, Ogle RF, Hennessy A. Acute Pulmonary Oedema asa Complication of Hypertension During Pregnancy. Hypertension Preg. 2011;30:169-79.

11. Blackburn S. Maternal, Fetal and Neonatal Physiology: A Clinical Perspective. $2^{\text {nd }}$ ed. St Louis: WB Saunders;2003.

12. Whitty J, Dombrowski M. Respiratory diseases in pregnancy. In: Creasy R, Resnik R, Iams J, eds. Maternal-fetal Medicine: Principles and Practice. 5th ed. Philadelphia: WB Saunders; 2004:953-74.

13. Gandhi S, Sun D, Park AL, Hladunewich M, Silversides CK, Ray JG. The Pulmonary Edema Preeclampsia Evaluation (PEPE) Study. J Obstet Gynaecol Can.2014;36(12):1065-70

14. O'Dwyer SL, Gupta M, Anthony J. Pulmonary edema in pregnancy and the puerperium: a cohort study of 53 cases. J. Perinat. Med. 2014;43(6):67581 .

15. Ganzevoort W, Rep A, Bonzel GJ. A randomised control trial comparing two temporising management strategies, one with and one without plasma volume expansion for severe and early onset pre-eclampsia. Br J Obstet Gynecol. 2005;112:1358-68.
16. Belfort M, Anthony J, Kirshon B. Respiratory function in severe gestational proteinuric hypertension: the effects of rapid volume expansion and subsequent vasodilatation with verapamil. BJOG 1991;98:964-72.

17. Brichant JF, Brichant G, Dewandre PY, Foidart JM. Hemodynamic and respiratory manifestations of preeclampsia. French Annals Anes Resuscitat. 2010;29:91-5

18. Bhorat I, Naidoo DP, Moodley J. Maternal cardiac haemodynamics in severe pre-eclampsia complicated by acute pulmonary oedema: A review. The Journal of Maternal-Fetal Neonat Med. 2017;30(23):276977.

19. Schobel HP, Fischer T, Heuszer K, Geiger H, Schmieder RE. Pre-eclampsia a state of sympathetic overactivity. New Eng J Med 1996;335:1480-5.

20. Mabie W. Pulmonary edema. In: Dildy GA III, BelfortM, Saade G, Phelan J, Hankins G, Clark S, eds. Critical Care Obstetrics. $4^{\text {th }}$ ed. Malden, Mass: Blackwell Science; 2004:346-53.

21. Poole JH. Spreen DT. Acute Pulmonary Edema in Pregnancy. J Perinat Neonat Nurs. 2005;19(4):31631

22. Raobijaona H, Andrianjanaka JC, Rakotorimanana DR. Rheumatic fever (RAA) has antananarivo (Madagascar). Med Black Africa. 1998;45:686-9..

23. Carlin A, Alfirevic Z. Physiological changes of pregnancy and monitoring. Best Pract Res Clin Obstet Gynaecol 2008;22:801-23.

24. Cantwell R, Clutton-Brock T, Cooper G, Dawson A, Drife J, Garrod D, et al. Saving Mothers' Lives: Reviewing maternal deaths tomake motherhood safer: 2006-2008. The Eighth Report of the Confidential Enquiries into Maternal Deaths in the United Kingdom. Br J Obstet Gynaecol. 2011;118(1):1-203.

25. National Committee for Confidential Enquiry into Maternal Deaths. Saving Mothers 2008 - 2010: The Fifth Report on Confidential Enquiries into Maternal Deaths in South Africa. Pretoria: National Department of Health; 2012.

26. Saving Mothers Report 2011-2013; National Dept of Health, Pretoria, 2015.

Cite this article as: Romuald $\mathrm{R}$, Tanjona RA, Fleurian S, Ibrahim A. Etiology and maternofetal issue of acute pulmonary edema in prepartum at the Befelatanana University Hospital of Gynecology and Obstetrics. Int J Reprod Contracept Obstet Gynecol 2018;7:3014-9. 